\title{
The Influence of Elision on the Original Syllabic Structure in English and Safwani Arabic: A Contextual Analysis
}

\author{
Majid Abdulatif Ibrahim ${ }^{1}$ \\ ${ }^{1}$ Department of English, Faculty of Arts \&Sciences, Middle East University, Jordan \\ Correspondence: Majid Abdulatif Ibrahim, Department of English, Faculty of Arts \& Sciences, Middle East \\ University, Jordan. E-mail: majidabd2@hotmail.com
}

Received: February 22, 2016 Accepted: March 13, 2016 Online Published: March 28, 2016

doi:10.5539/ijel.v6n2p1 URL: http://dx.doi.org/10.5539/ijel.v6n2p1

\begin{abstract}
Elision, as being a distinguishing mark among phonological processes, plays a vital role in patterning and mapping syllables of the language in a way that it can "distort" particular syllabic forms and templates. It represents deterioration, modification and to some extent radical changes in the syllabic structure of the original words even though it is usually a result of rapid colloquial speech. This study is a phonological work to detect the influence of sound deletion on syllabic templates and patterns of English and Safwani Arabic. It is an attempt to work out an analysis of the possible contexts where individual segments and syllables exhibit deletion. The analysis of all possible contexts where segments and syllables are lost in these varieties is illustrated by detailed tables within the paper. The tables are designed in a way that both original and reduced word or phrase forms are given, the context of sound elision is provided and then both original and resulting syllabic patterns are demonstrated.
\end{abstract}

Keywords: elision, syllabic structure, English, Safwani Arabic, analysis

\section{Introduction}

It has long been observed that elision, as being a phonological process, casts its shadow on patterning and mapping syllables of the language in a way that it can "sculpt" particular syllabic forms and templates. This syllabic "sculpture" affects the distribution of phonemes (consonants and vowels) within syllable boundary. In other words, two segments may be deleted and above all in certain contexts, segments tend either to change their major class features or to interchange. Elision represents deterioration, modification and to some extent radical changes in the syllabic structure of the original words even though it is usually a result of rapid colloquial speech.

This study is a phonological work to detect the influence of sound deletion on syllabic templates and patterns of English and Safwani Arabic. It is an attempt to work out an analysis of the possible contexts where individual segments and syllables exhibit deletion. The two varieties under this study are BBC English (formerly labeled as Received Pronunciation (RP, for short)), and Safwani Arabic, a dialect of a town in southeast Iraq on the border with Kuwait. The paper is chiefly based on analyzing two types of data: as far as English is concerned, the surveys of elision given in Gruttend (2008) and Brown (1993) are mainly adopted, simply because these two sources provide fairly thorough account of all the possible elisions occurring in English in different contexts. As for elision in Safwani Arabic, a survey of a previous work conducted by Woodhead \& Beene (1967) is carried out. Through this survey, all the lexical items and expressions in Iraqi Arabic are checked up. The analysis of all possible contexts where segments and syllables are lost in these varieties is illustrated by detailed tables within the paper.

\section{Elision: The Loss of Segments}

Elision is a phonological concept referring to the omission of sounds in connected speech. Not only consonants and vowels are sometimes subsumed under such an omission, but whole syllables are also lost. In a more technical way, elision can be viewed as zero realization of phonemes in which it occurs in certain circumstances as gradation of phonemes which implies the loss of consonants and vowels (Gruttendan, 2008; Roach, 2009). On the other hand, Jones $(1975$, p. 230) and Wells \& Colson (1971, p. 57) differentiate between historical elision where a sound which existed in an earlier form of a word is omitted in a later form, and contextual elision in 
which a sound being available in a word uttered by itself is dropped in a compound or in a connected phrase.

It is believed that elision varies in extent and frequency of occurrence in different languages and contexts. Brosnahan \& Malmberg (1970, p. 137) confirm that elision is "likely to be minimal in slow careful speech and maximal in rapid relaxed colloquial forms of speech". Accordingly, since most of languages show considerable variations of stress among syllables, deleted segments are more familiar and extensive in unstressed syllables. Other scholars (e.g., Hartmann \& Stork, 1972, p. 75) confine elision to the loss of phonemes that occur across syllable or word boundaries. They presume that such a process takes place in connected speech for the economy of effort and for the ease of pronunciation.

In generative phonology, elision is interpreted as a phonological process that affects the original syllabic structure of words. Schane (1973), for example, considers elision as a process that occurs within the syllabic structure of words to which he refers as "a syllable structure process". So, it is, in fact, the difference in syllabic structure that paves the way for phonemes to be dropped in certain contexts. Treating elision in English and in other languages, generative phonologists propose a number of rules to show what sounds are subjected to deletion and under which environments.

\section{The Syllable: The Necessity of Its Evolution}

Since the core of the present investigation is to specify the influence that elision may have on the syllable of both English and Safawi Arabic, it is found necessarily to tackle the syllable, which is one of the linguistic notions that has been studied thoroughly and extensively by a number of scholars. In fact, the syllable and vowel/consonant dichotomy have been manipulated from the earliest time in linguistic analysis. While vowels and consonants have been employed in the anatomy of words, the syllable has been used as the fundamental unit in the description of prosodic systems of languages and in verse forms based on prosodic patterns.

It is argued that the phonemic description of a language is not complete if it is confined only to establish the phoneme inventory and to examine the distinctive features of its members. So, the phonemic description should also account for the phoneme combinations that occur or that may be expected to occur in the language. These combinations confirm to particular patterns varying from one language to another, and it is possible to formulate a number of more or less general statements which deal with these patterns when the data available on that language is sufficient (Jackobson \& Halle, 1968).

The restrictions, imposed on the phonotactic possibilities permitted in every dialect or language, have been emphasized by many theorists' viewpoints. They suggest that the analysis of these restrictions and regularities is accomplished via studying the syllables of the dialect or the language concerned. It is proposed that the probabilities related to the various concatenations of phonemes are of immense value but they are easily achieved in the phonological description of the language. Such a difficulty is attributed to the problems inherent in selecting a representative sample of the language from which the possibilities of phoneme combinations can be identified in a meaningful manner. Phoneme concatenations may be specified within word-boundaries or across word-boundaries (Katamba, 1989; Roach, 2009).

In terms of other phonological approaches, different applications can be made to the phonological description of any particular language. Some of these applications involve generating utterances and others involve analyzing utterances. A complete statement of the phonemic part of the phonological component of a language should contain a set of rules for referring to the allophonic environmental statement in analyzing utterances (Peterson, 1968, p. 165).

According to the above assumptions, generative rules may be formulated to transform phone sequences of phone types. Hence, the generative rules of the phonemic part of the phonological description of a language should convert phoneme strings to string of phone types. In this process, any necessary prosodic and grammatical information are to be related to the phone sequences from which the phone types are generated. When an allophonic environmental statement has been constructed in the manner mentioned so far, it becomes easier to identify a set of rules for the analysis of utterances than might be anticipated.

The term "syllable" can possibly be identified via various definitions. The syllable definitions may be categorized into two major classes: phonetic and phonological definitions. In the first place, phonetic definitions imply acoustic-organic orientations, namely, distinctions have been made between articulatory and acoustic syllables. The former is constructed by the minimum groupings of articules and the latter by the minimum groupings of phones. At the phonological level, the phonemic or structural syllable is formed by certain selections and combinations of phonemes. The units isolated as syllables by particular criteria which are valid at one of these levels do not necessarily or always correspond exactly with the units separated at any other level. 
Moreover, the syllable at any level in one language does not agree with its counterpart in another language (Brosnahan \& Malmberg, 1970, p. 140).

\section{The Impact of Elision on the Syllable Structure: A New Reconstruction}

The effect imposed on the original syllable structure as a result of elision in English and Safwani Arabic occurs via many strategies adopted by the speakers of both language varieties in attempt to seek, in most cases, rapidity of speech or expenditure of effort. The most common strategies are as follows: (i) eliding the nucleus of initial unstressed short open syllable of the pattern /cv/ word-internally and across word-boundary where the remaining consonant functions as an initial element of two-element cluster, (ii) dropping the nucleus of unstressed short open syllable of the pattern $/ \mathrm{cv} /$ word-medially within one and the same word transferring the resulting consonant to be a coda of a preceding syllable, (iii) deleting the nucleus of unstressed complex syllable of the pattern $/ \mathrm{vcc} /$ in phrasal context where the remaining two consonants operate as initial and post-initial elements of initial three-element clusters, (iv) eliding the nucleus of unstressed simple closed syllable of the structure /cvc/ word-medially in the citation form transforming the remaining two consonants to work as final and post-final elements of a final two-element cluster, (v) deleting the nucleus of unstressed simple closed syllable of the pattern /cve/ in which the remaining two consonants are transferred in opposite direction; one as a coda of a preceding syllable and the other as an onset of a subsequent syllable, (vi) omitting the nucleus of unstressed simple open syllable of the pattern $/ \mathrm{cv} /$ in word-final position whereby the remaining consonant is attached to a coda of a preceding syllable, (vii) simplifying consonant clusters both within word-boundary or across word-boundary where such simplification occurs in different syllabic patterns, (viii) eliding certain consonants both in stressed and unstressed syllables affecting the original syllabic structure or in certain cases leading to unpermitted consonant combination, (ix) changing the original syllabic structure via changing its length as a result of eliding particular segments of the same syllable, (x) dropping both the onset and the nucleus some syllables, and (xi) changing the original syllabic structure within phrasal context via transferring the coda of a preceding syllable to be an onset of a subsequent syllable.

Table 1 outlines all the possible contexts in which vocalic segments, consonantal segments and complete syllables are dropped in English both word-internally and across word-boundary. Examples (1-5), and (9-20) point out respectively the loss of the short front vowel $/ \mathrm{I} /$, and the short central vowel /a/ in initial unstressed open syllable of the pattern $/ \mathrm{cv} /$. The loss of these vowels in such a context, as the table clearly indicates, affects the syllabic structure of the original syllable where elision takes place as well as the syllabic structure of the adjacent syllables, and it may also decrease the number of the original syllables. In all these instances, the resulting consonant plays the role of an initial element of two-consonant cluster. The formation of such clusters may lead, in some cases, to consonant combinations which are not permitted in English like /ph/, /ft/, /fn/, /vr/ and $/ \theta \mathrm{m} /$. This implies that elision may result in violating the phonotactic possibilities in English (see examples 9, $14,15,16$ and 17).

The elision of the two short vowels mentioned above in unstressed simple open syllable affect the syllabic structure of the preceding syllable. This stems from the transfer of the remaining consonant to be a coda of that syllable. That is, such deletion alters the preceding syllable into simple closed syllable instead of simple open one as shown in examples $6,7,18$ and 20.

In phrasal context, the short vowels /I/ and /a/ are dropped in word-initial position within unstressed complex closed syllable of the pattern $/ \mathrm{vcc} /$. The loss of these segments in such a position leads the remaining two consonants to work as initial and post-initial elements of three-consonant clusters which are formed across word-boundary. However, these clusters contradict the possibilities of sequential occurrence of phonemes permitted in English. For instance, /tsð/ may be formulated in word-combination (see example 8).

Example (19) of the Table 1 elucidates that the short central vowel /ə/ is dropped word-medially in unstressed simple closed syllable of the pattern /cve/ and not in unstressed open syllable of the pattern $/ \mathrm{cv} /$ whereby the resulting two consonants operate as final and post-final elements of a final two-consonant cluster to a preceding stressed syllable of the pattern /cv/. The schwa /a/ may also be deleted in pre-final position of unstressed simple closed syllable of the pattern $/ \mathrm{cvc} /$ where the remaining two consonants of that syllable are distributed in a reverse direction; one as a coda of a preceding syllable and the other as an onset of a subsequent syllable. This, in turn, decreases the number of the original syllables of the utterance where elision takes place and affects the syllabic structure of the neighboring syllables (see example 23).

In another context, the schwa/a/ is elided word-finally in unstressed simple open syllable of the pattern /cv/ whereby the lost schwa/a/ is followed by a lexeme starting with a consonant. This can be elicited in the examples (24), and (26) of the same table. Elision of this type affects the preceding syllable in a way that the 
resulting consonant is attached to the preceding syllable altering its pattern into $/ \mathrm{vc} /$ instead of $/ \mathrm{v} /$. The deletion of the schwa /a/ in word-final position may also lead to violate the rules of phonemic distribution in English. Example (25) confirms this fact in which the loss of such a vowel in word-final position across word-boundary yields in the initial two-element consonant combination $/ \mathrm{tm} /$ which is not allowed in English. Within word-combination, the deletion of the schwa /a/ which forms a syllable by itself causes the initial $/ \mathrm{n} /$ and $/ 1 /$ with which subsequent words begin to be transferred as syllabic consonants of preceding mono-syllabic words changing their pattern into $/ \mathrm{cvcc} /$ instead of $/ \mathrm{cvc} /$. This is what examples (21 and 22) clearly demonstrate.

In a variety of environments, consonantal segments in English are dropped in rapid colloquial speech. This elision occurs in both stressed and unstressed syllables of many patterns like /vc/, /cv/ and /cvc/. Such syllables alter their structures in accordance to the loss of their consonantal elements in which they may become of $/ \mathrm{v} /$, /cv/ and /vc/ patterns (see examples 33, 34 and35). For economy of energy, native speakers of English have a tendency to simplify consonant clusters within word-boundary and across word-boundary. Such simplification takes place in both stressed and unstressed syllables of different patterns like /cv/, /vcc/, /cvcc/, /cvccc/, and /ccvecc/ (see examples 28, 29, 30, 31 and 32).

Table 1. A contextual analysis of the possible segments and syllables elided in English

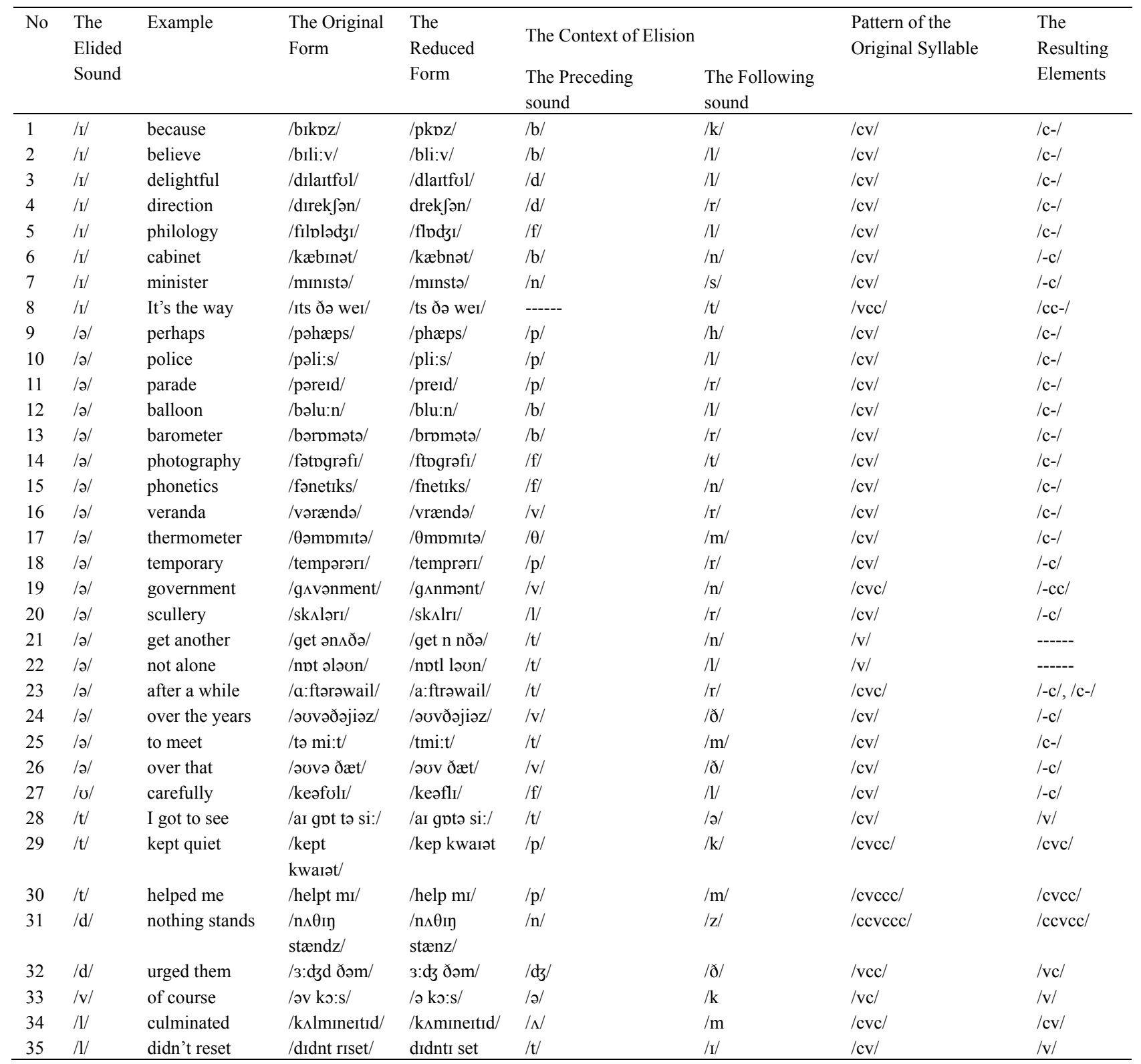


Table 2 surveys the possible contexts where both vowels and consonants are dropped in Safwani Arabic. Through a careful analysis to the data included, one can state that segmental elision in this language, as it is the case in English, has its remarkable effect on the original syllabic structure mainly via the alteration of the pattern of the original syllabic structure in which elision takes place and in certain cases this alteration affects the syllabic structure of the adjacent syllables both within word-boundary and across word-boundary decreasing the number of the original syllables.

Examples (1-8, 16-24 and 26-32) deal with the deletion of the short vowels /i/, /a/ and /u/ in unstressed initial short open syllable of the pattern /cv/ within word-boundary. Most of the lexemes presented are of classical origin where their pronunciation has been modified and it has been established whether the word is spoken in isolation or within a context. The loss of these segments leads to initial two-element clusters together with the reduction of the number of the original syllables. As the data reveal, the adjacent syllables next to the elided short vowels mentioned so far have been modified into /ccv/, /ccvc/, /ccvc/ and /ccvcc/ instead of /cv/, /cv/, /cvc/ and $/ \mathrm{cvcc} /$. This obviously indicates the tendency of Safwani speakers to get rid of open syllables by changing them into closed ones.

In a number of contexts, the front short vowel $/ \mathrm{i} /$ is deleted in word-medial position within unstressed short open syllable of the pattern $/ \mathrm{cv} /$. This elision leads to the transference of the resulting consonant to be a coda of a preceding open syllable. Examples (9-11) are good cases in point. The short vowels $/ \mathrm{i} / \mathrm{and} / \mathrm{a} / \mathrm{may}$ be dropped in Safwani Arabic across word-boundary within unstressed initial short syllable of the pattern /cv/. Unlike English, the loss of these segments in such a context seems to formulate initial two-element clusters which do not contradict the possibilities of sequential concatenation of phonemes permitted in the language (see examples 12 and 24), for instance. The same short vowels are also deleted within unstressed medium closed syllable of the pattern /cve/ where it occurs word-finally in phrasal context. A process like this causes the remaining two consonants to be marginal elements of a preceding stressed open syllable of the structure /cv/. That is, the preceding syllable is changed into a closed one instead of an open syllable. Such a type of elision can be illustrated in examples like (13, 14, 15 and 25).

Consonantal segments are lost in Safwani Arabic in different word-positions in the citation form and within phrasal context. This elision affects the original syllabic structure of lexemes and in certain environments it extends to involve the neighboring syllables (see examples 33-45). Seeking a simple articulation, Safwani speakers my elide one of the elements of initial and medial two-consonant clusters whether within word-boundary or in word-combination (see examples 33, 34, 44 and 45). However, the reduction of consonant clusters in this variety, which also has its effect on the syllabic structure, is of a limited range as compared to English. This is attributed to the fact that English exhibits clusters of more than two elements in different word-positions in comparison with Safwani Arabic where simplifying such clusters is a very common process. In consequence, the influence of such a process in English on the original syllabic patterning and syllabification is of a remarkable nature.

A number of instances $(28,39,40,41,42$ and 43) indicate that segmental elision in Safwani Arabic my change the original syllabic structure via lengthening or shorting the vowel which precedes the elided consonant. This phenomenon, however, occurs in English in phrasal context and not within word-boundary as compared with the former. In most cases, it is the diphthong preceding an elided schwa /a/ which is modified into a long vowel in English (for example, try again /trai əgern/ becomes /tra: gen/ and go away/gəu əweI/ becomes /g3: weI/) and not the short vowel which occurs before the deleted consonant as it is in Safwani Arabic. Modifying the syllabic structure in Safwani Arabic can be achieved via dropping both the onset and the nucleus of the syllable within one and the same word, and the onset and the nucleus or the nucleus and the coda in word-combination (see examples 46-49). 
Table 2. A contextual analysis of the possible segments and syllables elided in Safwani Arabic

\begin{tabular}{|c|c|c|c|c|c|c|c|c|}
\hline \multirow[t]{2}{*}{ No } & \multirow{2}{*}{$\begin{array}{l}\text { The } \\
\text { Elided } \\
\text { Sound }\end{array}$} & \multirow{2}{*}{$\begin{array}{l}\text { The Original } \\
\text { Form }\end{array}$} & \multirow[t]{2}{*}{ Meaning } & \multirow[t]{2}{*}{ The Reduced Form } & \multicolumn{2}{|c|}{ The Context of Elision } & \multirow{2}{*}{$\begin{array}{l}\text { Pattern of } \\
\text { the Original } \\
\text { Syllable }\end{array}$} & \multirow{2}{*}{$\begin{array}{l}\text { The } \\
\text { Resulting } \\
\text { Elements }\end{array}$} \\
\hline & & & & & $\begin{array}{l}\text { The Preceding } \\
\text { sound }\end{array}$ & $\begin{array}{l}\text { The Following } \\
\text { sound }\end{array}$ & & \\
\hline 1 & /i/ & bidūn & "without" & bdūn & $/ \mathrm{b} /$ & $/ \mathrm{d} /$ & $/ \mathrm{cv} /$ & /c-/ \\
\hline 2 & /i/ & di $\theta \bar{a} r$ & "cover" & d $\theta \bar{a} r$ & $/ \mathrm{d} /$ & $/ \theta /$ & $/ \mathrm{cv} /$ & /c-/ \\
\hline 3 & /i/ & kibār & “big (pl.) & kbār & $/ \mathrm{k} /$ & $/ \mathrm{b} /$ & $/ \mathrm{cv} /$ & /c-/ \\
\hline 4 & /i/ & qimār & "gambling" & qmār & /q/ & $/ \mathrm{m} /$ & $/ \mathrm{cv} /$ & /c-/ \\
\hline 5 & /i/ & dsināza & "funeral" & dłnāza & $/ d \mathrm{~d} /$ & $/ \mathrm{n} /$ & $/ \mathrm{cv} /$ & /c-/ \\
\hline 6 & /i/ & fitāt & "crumbs" & ftāt & $/ \mathrm{f} /$ & $/ \mathrm{t} /$ & $/ \mathrm{cv} /$ & /c-/ \\
\hline 7 & /i/ & ðinūb & "sins" & ðnūb & /ð/ & $/ \mathrm{n} /$ & $/ \mathrm{cv} /$ & /c-/ \\
\hline 8 & /i/ & silāl & "baskets" & slāl & $/ \mathrm{s} /$ & $/ 1 /$ & $/ \mathrm{cv} /$ & /c-/ \\
\hline 9 & /i/ & dāPiman & “always” & dāyman & $/ 2 /$ & $/ \mathrm{m} /$ & /cv/ & $\mid-c /$ \\
\hline 10 & /i/ & Sā?ila & "family" & ৎāyla & $/$ / / & /1/ & $/ \mathrm{cv} /$ & $\mid-c /$ \\
\hline 11 & /i/ & gilitilha & "I said to her" & gittilha & $/ 1 /$ & $/ \mathrm{t} /$ & $/ \mathrm{cv} /$ & $-\mathrm{c} /$ \\
\hline 12 & /i/ & $\min$ biSīd & "distantly" & $\min b \bigcap_{1} \bar{d}$ & $/ \mathrm{b} /$ & $/ \mathrm{S} /$ & /cv/ & /c-/ \\
\hline 13 & /i/ & xubiz Jịīr & "barley bread" & xubiz $\int Y_{1 ̄ r}$ & $/ \mathrm{b} /$ & $|z|$ & /cve/ & $|-c c|$ \\
\hline 14 & /i/ & ridit Pagūl & $\begin{array}{l}\text { "I wanted to } \\
\text { say" }\end{array}$ & ritt agūl & $/ \mathrm{d} /$ & $/ \mathrm{t} /$ & /cve/ & $/-\mathrm{cc} /$ \\
\hline 15 & /i/ & $m u \bar{~} \int a r i t^{\varsigma}$ & “unnecessary” & $m \bar{u} \int \operatorname{art}^{\varsigma}$ & $/ \mathrm{r} /$ & $/ \mathrm{t} /$ & /cve/ & $|-c c|$ \\
\hline 16 & $/ \mathrm{a} /$ & $\operatorname{bas}^{\mathrm{C}} \bar{a} t^{\mathrm{S}} \overline{1} \mathrm{l}$ & "boots" & $b s^{\varsigma} \bar{a} t^{\Upsilon} \overline{1} l$ & $/ \mathrm{b} /$ & $/ \mathrm{s}^{\mathrm{q}} /$ & /cv/ & /c-/ \\
\hline 17 & $/ \mathrm{a} /$ & tafā?al & "optimistic" & tfā?al & $/ \mathrm{t} /$ & /f/ & /cv/ & /c-/ \\
\hline 18 & $/ \mathrm{a} /$ & damāy & "brain" & dmāy & $/ \mathrm{d} /$ & $/ \mathrm{m} /$ & $/ \mathrm{cv} /$ & /c-/ \\
\hline 19 & $/ \mathrm{a} /$ & kaAīr & "too much" & $\mathrm{k} \theta \overline{\mathrm{i}} \mathrm{r}$ & $/ \mathrm{k} /$ & $/ \theta /$ & $/ \mathrm{cv} /$ & /c-/ \\
\hline 20 & $/ \mathrm{a} /$ & fanādzīn & "coffee-pots" & fnādzīn & /f/ & $/ \mathrm{n} /$ & /cv/ & /c-/ \\
\hline 21 & $/ \mathrm{a} /$ & d'afāPir & "locks of hair" & d`fāyir & $/ \mathrm{d}^{\mathrm{\varsigma} /}$ & $/ \mathbf{f} /$ & $/ \mathrm{cv} /$ & /c-/ \\
\hline 22 & $/ \mathrm{a} /$ & sawāqi & "water tunnels" & swāgi & /s/ & /w/ & $/ \mathrm{cv} /$ & /c-/ \\
\hline 23 & $/ \mathrm{a} /$ & xalāl & "dates" & xlāl & $/ \mathrm{x} /$ & $/ 1 /$ & /cv/ & /c-/ \\
\hline 24 & $/ \mathrm{a} /$ & Sala mūdak & "for your sake" & Sla mūdak & $/ \mathrm{S} /$ & $/ 1 /$ & /cv/ & /c-/ \\
\hline 25 & $/ \mathrm{a} /$ & baład fwayy & " for a while" & baSd ifwayy & $/ \mathrm{S} /$ & $/ \mathrm{d} /$ & /cve/ & $\mid-\mathrm{cc} /$ \\
\hline 26 & $/ \mathrm{u} /$ & buxūr & "incense" & bxūr & $/ \mathrm{b} /$ & $/ \mathrm{x} /$ & /cv/ & /c-/ \\
\hline 27 & $/ \mathrm{u} /$ & tusā̧id & "to help" & tsā̧id & $/ \mathrm{t} /$ & $/ \mathrm{s} /$ & /cv/ & /c-/ \\
\hline 28 & $/ \mathrm{u} /$ & duyūn & "debts" & dyūn & $/ \mathrm{d} /$ & $/ \mathrm{y} /$ & $/ \mathrm{cv} /$ & /c-/ \\
\hline 29 & $/ \mathrm{u} /$ & ḑuðū؟ & "tree trucks" & ḑðū & $/ d \mathrm{~d} /$ & /ð/ & $/ \mathrm{cv} /$ & /c-/ \\
\hline 30 & $/ \mathrm{u} /$ & fuћūl & "males" & fhūl & $/ \mathrm{f} /$ & $/ \hbar /$ & /cv/ & /c-/ \\
\hline 31 & $/ \mathrm{u} /$ & surūds & "suddles" & srūds & $/ \mathrm{s} /$ & $/ \mathrm{r} /$ & $/ \mathrm{cv} /$ & /c-/ \\
\hline 32 & $/ \mathrm{u} /$ & Juqūq & "holes" & $\int g u \bar{g} g$ & $/ \mathrm{d} /$ & $/ g /$ & /cv/ & /c-/ \\
\hline 33 & $/ \mathrm{b} /$ & bkēfi & "as I wish" & kēfi & ------ & $/ \mathrm{k} /$ & /ccv/ & /cve/ \\
\hline 34 & $/ \mathrm{b} /$ & bkēf ?alla & "as God wills" & kēf falla & ------ & $/ \mathrm{k} /$ & /ccve/ & $/ \mathrm{cvc} /$ \\
\hline 35 & $/ \mathrm{b} /$ & xōb mā ziৎal & "is he huffied?" & xō mā ziৎal & $/ \overline{\mathbf{o}} /$ & $/ \mathrm{m} /$ & /cve/ & /cv/ \\
\hline 36 & $/ \mathrm{t} /$ & s'alāt & "prayer" & $\mathrm{S}^{\Upsilon}$ alā & $/ \overline{\mathrm{a}} /$ & ------ & /cve/ & $/ \mathrm{cv} /$ \\
\hline 37 & $/ \mathrm{t} /$ & hayāt wmōt & "life and death" & ћayā wmōt & $/ \overline{\mathrm{a}} /$ & $/ \mathrm{w} /$ & $/ \mathrm{cvc} /$ & $/ \mathrm{cv} /$ \\
\hline 38 & $/ 2 /$ & Pa?man & "safer" & Pāman & $/ \mathrm{a} /$ & $/ \mathrm{m} /$ & /cve/ & $/ \mathrm{cv} /$ \\
\hline 39 & $/ 2 /$ & ma?mūn & "trust" & māmūn & $/ \mathrm{a} /$ & $/ \mathrm{m} /$ & /cve/ & $/ \mathrm{cv} /$ \\
\hline 40 & $/$ / / & ta?rīx & "history" & tārīx & $/ \mathrm{a} /$ & $/ \mathrm{r} /$ & /cve/ & $/ \mathrm{cv} /$ \\
\hline 41 & $/ \mathrm{l} /$ & lu?lu? & "pearl” & lūlu & $/ \mathrm{u} /$ & $/ 1 /$ & /cve/ & $/ \mathrm{cv} /$ \\
\hline 42 & $/ \mathrm{R} /$ & barī? & "innocent" & bari & $/ \overline{1} /$ & ----- & /cve/ & $/ \mathrm{cv} /$ \\
\hline 43 & $/$ / / & Samyā? & "blind (fem.)" & Samya & $/ \overline{\mathrm{a}} /$ & ----- & /cve/ & /cv/ \\
\hline 44 & $/ \mathrm{S} /$ & sbuYt ${ }^{\varsigma} a a_{a}$ & "seventeen" & sbut'aSas & $/ \mathrm{u} /$ & $/ \mathrm{t} /$ & /ccve/ & $/ \mathrm{ccv} /$ \\
\hline 45 & $/ \mathrm{h} /$ & Sinhu hāy & "what is it?" & Jinu āy & $/ \mathrm{n}, \mathrm{u} /$ & $/ \mathrm{u}, \overline{\mathrm{a}} /$ & ------ & $/ \mathrm{v} /, / \mathrm{vc} /$ \\
\hline 46 & $/ \mathrm{n}+\mathrm{a} /$ & yikirhūnak & "they hate you" & ykirhūk & $/ \mathrm{y}, \overline{\mathrm{u}} /$ & $/ \mathrm{k}, \mathrm{k} /$ & /cv,cve / & /c, c/ \\
\hline 47 & $/ \mathrm{i}+\mathrm{d} /$ & gā̧id yiqra & "he is reading" & gā̧ yiqra & $/ \mathrm{S} /$ & $/ \mathrm{y} /$ & /cve/ & /c/ \\
\hline 48 & $/ \mathrm{a}+\mathrm{d} /$ & baSad Jinu & "what else" & baৎ Jinu & $/ \mathrm{S} /$ & $/ \mathrm{d} /$ & /cve/ & $/ \mathrm{c} /$ \\
\hline 49 & $/ \mathrm{a}+1 /$ & Salal winsa & "on pleasure" & Sal winsa & $/ 1 /$ & $/ \mathrm{w} /$ & /cve/ & $/ \mathrm{c} /$ \\
\hline
\end{tabular}

\section{Conclusions}

The present study lucidly uncovers that the difference between English and Safwani Arabic as far as the elided syllables are concerned lies in the patterns of these syllables, their distribution and the elements with which they are formed. Elision in these two varieties has an effective hand on the distribution of phonemes word-internally 
and across word-boundary to various degrees. This influence is reflected mainly through the alternation of the patterns of the syllabic structure of words which is accompanied in most cases by a decrease in the number of the original syllables. Moreover, it has been noted that elision violates the phonotactic possibilities permitted in these language varieties where elision leads to the formation of consonant combinations not allowed.

\section{References}

Brosnahan, L., \& Malmberg, B. (1970). Introduction to Phonetics. Cambridge: Cambridge University Press.

Brown, G. (1993). Listening to Spoken English. London: Longman.

Cruttenden, A. (2008). Gimson's Pronunciation of English. London: Edward Arnold.

Hartmann, R., \& Stork, F. (1972). Dictionary of Language and Linguistics. London: Applied Science.

Jackbson, R., \& Halle, M. (1968). Phonology in Relation to Phonetics. In B. Malmberg (Ed.), Manual of Phonetics (pp. 411-449). London: North-Holland Publishing Company.

Jones, D. (1975). An Outline of English Phonetics. Cambridge: Cambridge University Press.

Katamba, F. (1989). An introduction to Phonology. London: Longman.

Peterson, G. (1968). The Speech Communication Processes. In B. Malmberg (Ed.), Manual of Phonetics (pp. 155-172). London: North-Holland Publishing Company.

Roach, P. (2009). English Phonetics and Phonology. Cambridge: Cambridge University Press.

Schane, S. (1973). Generative Phonology. New Jersey: Prentice-Hall.

Wells, J., \& Colson, G. (1971). Practical Phonetics. London: Pitman.

Woodhead, D., \& Beene, W. (1967). A Dictionary of Iraqi Arabic. Washington: Georgetown University Press.

\section{Appendix A}

\section{English Phonemic Symbols}

\section{The vowels:}

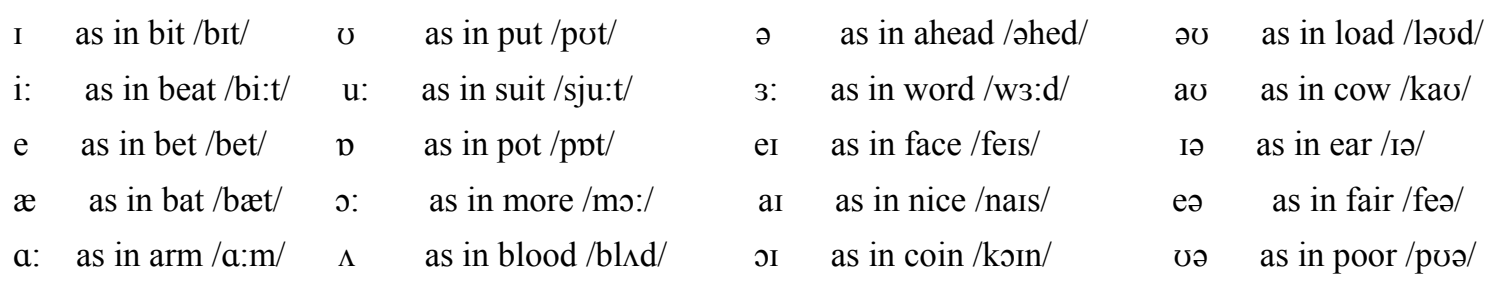

\section{The consonants:}

\begin{tabular}{|c|c|c|c|}
\hline p & as in pray /preI/ & $\int$ & as in she /fi:/ \\
\hline & as in bee /bi:/ & 3 & as in measure /mezo/ \\
\hline & as in tame /term/ & $\mathrm{h}$ & as in heat /hi:t/ \\
\hline & as in door /d॰:/ & t & as in choice /tyors/ \\
\hline & as in $\mathrm{kid} / \mathrm{kId} /$ & ds & as in jam /djæm/ \\
\hline & as in go /gəo/ & $\mathrm{m}$ & as in $\operatorname{mood} / \mathrm{mu}: \mathrm{d} /$ \\
\hline & as in feed /fi:d/ & $\mathrm{n}$ & as in night /nart/ \\
\hline & as in view /vju:/ & $\mathrm{y}$ & as in sing /sin/ \\
\hline & as in theft $/ \theta \mathrm{eft} /$ & 1 & as in less /les/ \\
\hline & as in this /ðIS/ & $\mathrm{r}$ & as in read /ri:d/ \\
\hline & as in sense /sens/ & $\mathrm{w}$ & as in we /wi:/ \\
\hline & as in zoo /zu:/ & $\mathrm{j}$ & as in yes /jes/ \\
\hline
\end{tabular}




\section{Appendix B}

\section{Safwani Phonemic Symbols}

\section{The Vowels:}

$\mathrm{i}$ as in dzibin "cheese"

a as in mal؟ab "playing field"

$\mathrm{u}$ as in dumbig "drum"

\section{The Consonants:}

b as in bōs "kises"

t as in talfān "spoiled"

$t^{\varsigma} \quad$ as in $t^{\varsigma} \overline{1} n$ "mud"

d as in dmū c "tears"

$\mathrm{d}^{\complement}$ as in d`ābut "officer"

$\mathrm{k}$ as in kimal "completed"

g as in gwāni "sacks"

? as in Pamay "blind"

$\mathrm{f}$ as in fazha "effort"

$\theta \quad$ as in $\theta$ āni "second"

ð as in ðе̄l "tail"

$ð^{\varsigma}$ as in ð`aruf "envelop" $\overline{1}$ as in birmīl "barrel"

$\bar{a}$ as in wās st $^{\mathrm{s} a}$ "medium"

$\overline{\mathrm{u}}$ as in hdūm "clothes" $\overline{\mathrm{e}}$ as in wēn "where

$\overline{0}$ as in xōf "fear"

\section{Copyrights}

Copyright for this article is retained by the author(s), with first publication rights granted to the journal.

This is an open-access article distributed under the terms and conditions of the Creative Commons Attribution license (http://creativecommons.org/licenses/by/3.0/). 